\title{
Integrated Management Strategies (Diagnosis, Treatment, and Wound Care Management) for Improved Clinical Outcomes of Buruli Ulcer in Ghana: A Retrospective Case Report in the Ga West Municipal Hospital, Amasaman
}

\section{Gideon Atinga Akolgo ${ }^{1}$, Anthony Ablordey², Janet Pereko ${ }^{3}$, Joseph Tuffour ${ }^{3}$, Nana Konama Kotey 4 , Albert Paintsil', Gladys Adwapa ${ }^{3}$, Akosua Agyapomaa Croffie ${ }^{3}$, Samuel Kwarteng Donkoh ${ }^{3}$ and Richard Amewu ${ }^{1 *}$}

${ }^{1}$ Department of Chemistry, University of Ghana, Legon-Accra, Ghana

${ }^{2}$ Noguchi Memorial Institute for Medical Research, University of Ghana, Ghana

${ }^{3}$ Ga West Municipal Hospital, Ghana Health Service, Ghana

${ }^{4}$ National Buruli Ulcer Program Manager, Ghana

${ }^{5}$ Department of Surgery, Korle Bu Teaching Hospital, Ghana

*Corresponding author: Richard Amewu, Department of Chemistry, University of Ghana, Legon-Accra, P.O. Box LG56, Ghana, Tel: +233-54-382-3483

\begin{abstract}
Buruli ulcer is a necrotizing skin infection caused by Mycobacterium ulcerans. BU lesions may start with characteristic painlessness but most often, the typical presentations of the disease are characterized by large ulcers with undermined edges. If left untreated, BU lesions may result in extensive ulceration that can cover $15 \%$ of the body. Even though public sensitization and education have resulted in sufficient and improved knowledge about the etiology of the disease in Ghana, patients still report to health facilities with advanced forms of the disease. As a result, the management of Buruli ulcer (BU) is increasingly becoming a challenge. Therefore, this case report highlights an integrated approach comprising of clinical diagnosis, laboratory confirmation, antibiotic treatment, and wound management of four confirmed cases of Buruli ulcer diseases that were managed at the BU Ward of the $\mathrm{Ga}$ West Municipal Hospital. Surgical interventions including debridement and skin grafting coupled with comprehensive wound care and/or physiotherapy were also employed in instances where antibiotic therapy alone was not sufficient for complete healing. The application of integrated management led to full recovery of all the patients, albeit with different times to healing depending on the severity of the lesions.
\end{abstract}

\begin{abstract}
Keywords
Buruli ulcer, Mycobacterium ulcerans, Case report, Mycolactone, Wound care, Mycolactone, surgery, Antibiotic therapy, Streptomycin, Rifampicin, Physiotherapy, Diagnosis, Treatment
\end{abstract}

\begin{abstract}
Abbreviations
ACL: Anterior Cruciate Ligament; BU: Buruli Ulcer; FNA: Fine Needle Aspirate; f-TLC: fluorescent-Thin Layer Chromatography; GWMH: Ga West Municipal Hospital; IRB: Institutional Review Board; M. ulcerans: Mycobacterium ulcerans; NBUCP: National Buruli Ulcer Control Program; NMIMR: Noguchi Memorial Institute for Medical Research; PCR: Polymerase Chain Reaction; ROM: Range of Motion
\end{abstract}

\section{Introduction}

Buruli ulcer (BU), a neglected tropical disease, is caused by Mycobacterium ulcerans. Globally, it is the third most common mycobacteriosis after tuberculosis and leprosy $[1,2]$. Buruli ulcer infection leads to the destruction of skin and soft tissue, presenting as large ulcers usually on the limbs [3]. Thus far, BU has been

Citation: Akolgo GA, Ablordey A, Pereko J, Tuffour J, Kotey NK, et al. (2022) Integrated Management Strategies (Diagnosis, Treatment, and Wound Care Management) for Improved Clinical Outcomes of Buruli Ulcer in Ghana: A Retrospective Case Report in the Ga West Municipal Hospital, Amasaman. Clin Med Rev Case Rep 9:379. doi.org/10.23937/2378-3656/1410379

Accepted: January 28, 2022: Published: January 30, 2022

Copyright: (c) 2022 Akolgo GA, et al. This is an open-access article distributed under the terms of the Creative Commons Attribution License, which permits unrestricted use, distribution, and reproduction in any medium, provided the original author and source are credited. 
reported in 33 countries in Africa, the Americas, Asia, and the Western Pacific. Most cases occur in tropical and subtropical regions, except for Australia, China, and Japan [3,4]. In West and Central Africa, Benin, Cameroon, Côte d'Ivoire, Democratic Republic of Congo (DRC) and Ghana have reported most cases [48]. Ghana, the second BU most endemic country in the world reports about 1,000 cases of BU annually [9].

Buruli ulcer disease has variable clinical presentation based on geography; in the pacific regions, for instance, it may start as a papule, whereas in West and Central Africa, it may start as a painless nodule without the involvement of subcutaneous tissues [10]. The disease generally occurs in stages with initial manifestations as painless pre-ulcerative subcutaneous nodules, a plaque, or as a rapidly progressing oedema. Oedema is the severe form of the disease and breaks down to form characteristic ulcers with undermined edges which can progress to large necrotic lesions that, if untreated, can extend to $15 \%$ of a patient's skin surface [11]. These ulcers are classified into three categories in terms of severity: Category I, a single lesion $<5 \mathrm{~cm}$ in diameter, Category II, a single lesion $5-15 \mathrm{~cm}$ in diameter and Category III, a single lesion $>15 \mathrm{~cm}$ in diameter, multiple lesions, critical sites, and osteomyelitis [12]. A relevant measure of early reporting is the size of the lesion, which is reflected by the World Health Organization (WHO) categorization system for BU. In this system, a category I lesion is below $5 \mathrm{~cm}$ in cross-sectional diameter, a category II lesion is between 5 and $15 \mathrm{~cm}$ in diameter, and a category III lesion is larger than $15 \mathrm{~cm}$ in diameter or involving critical sites (e.g., the eye or genitals) [12].

Despite the knowledge about the etiology of $\mathrm{BU}$, there is evidence of late reporting of many BU patients to health facilities for diagnosis; about $90 \%$ of patients in Africa present too late, with extensive lesions that cause severe disabilities [13]. A consequence of late reporting is high disabilities related to $\mathrm{BU}$ even though recorded mortalities are low. A recent study estimated that $66 \%$ of those with healed lesions have disabilities [13].

Traditionally, the treatment in ulcerative BU lesions required wide surgical removal of all the affected tissue and surrounding tissues up to the healthy tissue, and subsequent skin grafting $[10,13]$. For larger ulcers, this guideline implied extensive surgical procedures and prolonged hospitalization, leaving behind extensive scars, disfigurement, and contractures [14,15]. The foremost challenge however was that surgical treatment was often difficult to access in most endemic areas $[16,17]$. Furthermore, socio-economic factors such as surgical and treatment costs, prolonged hospital stay, and stigmatization prevented BU patients from seeking treatment. In addition, losses of school time by children, loss of earnings by parents or caregivers, and a large economic burden, directly and indirectly, affect families in severe cases result in a delay in seeking medical care and sometimes prohibited many patients from receiving this type of treatment $[15,18,19]$. Therefore, the introduction of antibiotic treatment by the World Health Organization (WHO) in 2004 revolutionized case management and improved clinical outcomes of BU disease. Since 2004, the WHO recommended firstline treatment for $\mathrm{BU}$ to be oral rifampicin $(10 \mathrm{mg} / \mathrm{kg})$ plus intramuscular streptomycin injection $(15 \mathrm{mg} / \mathrm{kg})$, both given daily for 8 weeks [11]. The recommended standard regimens are highly effective in killing the bacterium. There is evidence that all forms of Buruli ulcer (i.e., papules, nodules, plaques, oedema, and ulcers), however extensive, respond well to the use of standardized antibiotic treatment. It is reported that between $30 \%$ and $50 \%$ of patients are treated solely with antibiotics, thus limiting surgery to large ulcers thus drastically reducing the need for hospitalization, especially when cases are detected and diagnosed early [20-22].

Nonetheless, conservative surgery, in particular, debridement and skin grafting remain a part of Buruli ulcer treatment. This is because these procedures may be necessary in some cases to aid the healing of extensive ulcers (category II and III), thereby shortening the duration of hospitalization, and minimizing scarring that might limit movement [11]. Overall, ulcers, whether present initially or occurring during treatment of nonulcerative lesions, should be managed with regular and proper wound care and dressings, coupled with physiotherapy to maintain joint movement until healing is complete. Physiotherapy has become an integral part of BU therapy to prevent functional limitations and disability in severe cases. There is also the need for longterm rehabilitation for those left with disabilities [23].

This observational, retrospective cohort study strategies an integrated case management approach of effective diagnosis, antibiotic therapy, wound care, surgical interventions, and/or physiotherapy in the healing outcomes among four Buruli ulcer patients that were seen at the Buruli Ward of Ga West Municipal Hospital (GWMH), Amasaman.

\section{Case Description}

This was a retrospective descriptive cohort study of BU four (4) cases with category II and/or III Buruli ulcer scars that were seen and managed at the Buruli Ward of Ga West Municipal Hospital (GWMH), Amasaman, between 18 March 2016 to December 2020. The data for the study were obtained through a retrospective review of patient records at the BU clinic of Ga West Municipal Hospital. The hospital was provided with all drugs from the National Buruli Control Program. Definitions used for the study can be found in Table 1. 
Table 1: Parameter definitions used during analysis.

\begin{tabular}{|c|c|}
\hline Item & Definition \\
\hline Buruli ulcer case & $\begin{array}{l}\text { - Lesions were clinically assessed to be consistent with Buruli ulcer lesions by experts. } \\
\text { - Lesions positive for M. ulcerans by PCR and positive for mycolactone detection by f-TLC } \\
\text { from a swab or fine needle aspirates (FNA). }\end{array}$ \\
\hline Surgical definitions & $\begin{array}{l}\text { - Major surgery: Closure of an excised lesion using a split skin or full-thickness skin graft or } \\
\text { vascularized tissue flap. }\end{array}$ \\
\hline $\begin{array}{l}\text { Long-course } \\
\text { Antibiotics }\end{array}$ & - Duration of antibiotics 8 weeks (56 days) \\
\hline Treatment success & $\begin{array}{l}\text { - Healing of the entire lesion without recurrence after the antibiotic treatment course had been } \\
\text { completed. }\end{array}$ \\
\hline Treatment outcomes & $\begin{array}{l}\text { - } \quad \text { Antibiotic treatment completed. } \\
\text { - } \quad \text { Antibiotic treatment not completed. } \\
\text { - } \text { Healed without surgery. } \\
\text { - } \quad \text { Healed with surgery. } \\
\text { - } \quad \text { Healed without limitation of movement to any joint. } \\
\text { - } \quad \text { Healed with limitation of movement to any joint. }\end{array}$ \\
\hline
\end{tabular}

Table 2: Baseline characteristics, diagnosis, treatment received, surgical interventions and treatment outcomes of cases.

\begin{tabular}{|c|c|c|c|c|}
\hline & Case 1 & Case 2 & Case 3 & Case 4 \\
\hline Age & 6 years & 17 years & 14 years & 45 years \\
\hline Gender & Male & Male & Male & Male \\
\hline Date of specimen collection & 30th November, 2016 & $9^{\text {th }}$ January, 2019 & $24^{\text {th }}$ July, 2019 & $26^{\text {th }}$ September, 2020 \\
\hline Location of lesion(s) & Left upper limb/wrist & $\begin{array}{l}\text { Right lower limb/ } \\
\text { knee, thigh, and leg }\end{array}$ & $\begin{array}{l}\text { Right upper limb/arm } \\
\text { and forearm }\end{array}$ & Left lower limb/leg \\
\hline Lesion type & Ulcer & Ulcer & Ulcer & Ulcer \\
\hline $\begin{array}{l}\text { Clinical form, size, and WHO } \\
\text { category of the lesion }\end{array}$ & Category II & Category III & Category III & Category III \\
\hline $\begin{array}{l}\text { Specimen collected for PCR } \\
\text { diagnosis }\end{array}$ & $\begin{array}{l}\text { Dry swabs and FNA } \\
\text { in } 1 \mathrm{~mL} \text { phosphate } \\
\text { buffered saline } \\
\text { (PBS) }\end{array}$ & $\begin{array}{l}\text { Dry swabs in sterile } \\
\text { tubes }\end{array}$ & $\begin{array}{l}\text { Dry swabs in sterile } \\
\text { tubes }\end{array}$ & $\begin{array}{l}\text { Dry swabs in sterile } \\
\text { tubes }\end{array}$ \\
\hline $\begin{array}{l}\text { Specimen collected for f-TLC } \\
\text { diagnosis }\end{array}$ & $\begin{array}{l}\text { Swabs in O-ring } \\
\text { vials containing } \\
1 \mathrm{~mL} \text { absolute } \\
\text { ethanol, wrapped in } \\
\text { aluminium foil }\end{array}$ & $\begin{array}{l}\text { Swabs in O-ring } \\
\text { vials containing } \\
1 \mathrm{~mL} \text { absolute } \\
\text { ethanol, wrapped in } \\
\text { aluminium foil }\end{array}$ & $\begin{array}{l}\text { Swabs in O-ring } \\
\text { vials containing } 1 \\
\mathrm{~mL} \text { absolute ethanol, } \\
\text { wrapped in aluminium } \\
\text { foil }\end{array}$ & $\begin{array}{l}\text { Swabs in O-ring } \\
\text { vials containing } 1 \\
\mathrm{~mL} \text { absolute ethanol, } \\
\text { wrapped in aluminium } \\
\text { foil }\end{array}$ \\
\hline Date of laboratory diagnosis & December, 2016 & January, 2019 & July, 2019 & June, 2020 \\
\hline PCR results & Positive & Negative & Positive & Positive \\
\hline f-TLC results & Positive & Positive & Positive & Positive \\
\hline $\begin{array}{l}\text { Drug regimen } \\
\text { - } \quad \text { Principal drug } \\
\text { - } \quad \text { Secondary drug }\end{array}$ & $\begin{array}{l}\text { Rifampicin } \\
(10 \mathrm{mg} / \mathrm{kg}) \\
\text { streptomycin } \\
\text { injection }(15 \mathrm{mg} / \mathrm{kg})\end{array}$ & $\begin{array}{l}\text { Rifampicin } \\
(10 \mathrm{mg} / \mathrm{kg}) \\
\text { streptomycin } \\
\text { injection }(15 \mathrm{mg} / \mathrm{kg})\end{array}$ & $\begin{array}{l}\text { Rifampicin } \\
(10 \mathrm{mg} / \mathrm{kg}) \\
\text { streptomycin injection } \\
(15 \mathrm{mg} / \mathrm{kg})\end{array}$ & $\begin{array}{l}\text { Rifampicin } \\
(10 \mathrm{mg} / \mathrm{kg}) \\
\text { streptomycin injection } \\
(15 \mathrm{mg} / \mathrm{kg})\end{array}$ \\
\hline Duration of drug therapy & 8 weeks & 8 weeks & 8 weeks & 8 weeks \\
\hline Surgical treatment & No & No & Yes & No \\
\hline $\begin{array}{l}\text { Types of surgical } \\
\text { Interventions }\end{array}$ & $\mathrm{N} / \mathrm{A}$ & N/A & $\begin{array}{ll}\text { - } & \text { Debridement } \\
\text { - } & \text { Skin graft }\end{array}$ & N/A \\
\hline
\end{tabular}




\begin{tabular}{|c|c|c|c|c|}
\hline Treatment outcomes & $\begin{array}{ll}\text { - } & \text { Antibiotic } \\
\text { treatment } \\
\text { completed. } \\
\text { - } & \text { Healed without } \\
\text { surgery. } \\
\text { - Healed without } \\
\text { limitation of } \\
\text { movement to } \\
\text { any joint. }\end{array}$ & $\begin{array}{ll}\text { - } & \begin{array}{l}\text { Antibiotic } \\
\text { treatment } \\
\text { completed. }\end{array} \\
\text { - } & \text { Healed without } \\
\text { surgery. } & \text { Healed with } \\
\text { limitation of } \\
\text { movement to } \\
\text { any joint. }\end{array}$ & $\begin{array}{l}\text { - Antibiotic } \\
\text { treatment } \\
\text { completed. } \\
\text { - Healed with } \\
\text { surgery. } \\
\text { - Healed with } \\
\text { limitation of } \\
\text { movement to any } \\
\text { joint. }\end{array}$ & $\begin{array}{l}\text { - Antibiotic treatment } \\
\text { completed. } \\
\text { - Healed without } \\
\text { surgery. } \\
\text { - Healed without } \\
\text { limitation of } \\
\text { movement to any } \\
\text { joint. }\end{array}$ \\
\hline Date of laboratory diagnosis & $30^{\text {th }}$ November, 2016 & $9^{\text {th }}$ January, 2019 & $24^{\text {th }}$ July, 2019 & $26^{\text {th }}$ September, 2020 \\
\hline Date of discharge & 15 March 2017 & 15 July, 2020 & 15 July, 2020 & 15 July, 2020 \\
\hline Length of hospital stay & 105 days & 553 days & 357 days & 144 days \\
\hline
\end{tabular}
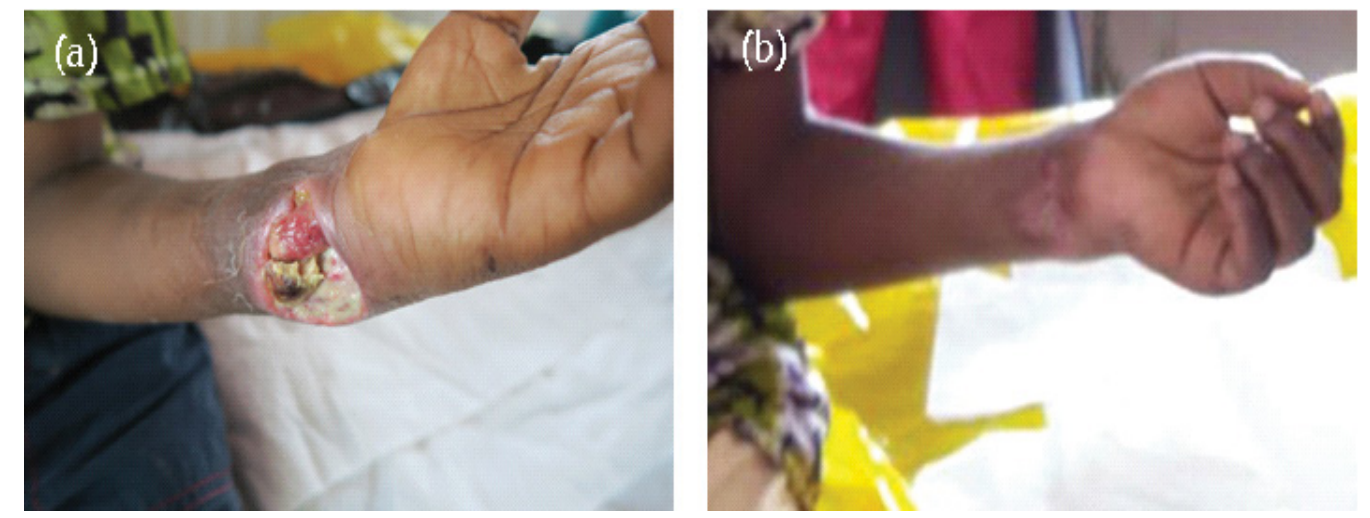

Figure 1: Mycobacterium ulcerans lesion on the left wrist on (a) Reporting (November 30, 2016) and at the start of antibiotics treatment; (b) 8 weeks after the start of antibiotics treatment.

\section{Baseline Characteristics, Diagnosis, Treatment} Received, Surgical Interventions, and Treatment Outcomes of Cases

Baseline characteristics, diagnosis, treatment received, surgical interventions, and treatment outcomes of all four cases are detailed in Table 2. Clinical photographs are shown in Figure 1, Figure 2, Figure 3 and Figure 4. All patients gave informed consent for publication. In all patients, the diagnosis of $M$. ulcerans was confirmed by positive polymerase chain reaction (PCR) and detection of mycolactone by fluorescent-thin layer chromatography ( $f-T L C)$ method from either swabs or fine needle aspirates (FNA) obtained before treatment. All samples for both f-TLC and PCR tests were transported in an ice chest with ice packs from the clinics to the Department of Chemistry, and Bacteriology Department of the Noguchi Memorial Institute for Medical Research (NMIMR), University of Ghana, Legon for f-TLC and PCR analyses, respectively. All four cases had ulcerative lesions and were confirmed positive by PCR and f-TLC results respectively (Table 2 : cases 1-4) and were treated with an antibiotic regimen of rifampicin combined with streptomycin for 8 weeks (56 days) as recommended by WHO [11]. Surgical treatment was performed on one case (Table 2). In addition to the surgical treatment, physiotherapy was required for two cases. Two cases healed completely without surgery and limitation of movement to any joint. The healing duration for all cases ranges from 105 to 553 days.

\section{Case 1}

Case 1 was a 6-year-old boy from Pokuase Amanfrom from the Ga East Municipality. The patient reported early to the facility in the nodular stage of the ulcer. He first reported to the Buruli Unit of the Ga West Municipal Hospital, Amasaman on November 30, 2016, with an initial non-painful nodule on the left wrist. On the first presentation, the patient was in good overall physical condition. However, by December 22, 2016, the nodule had rapidly progressed from a non-ulcerated lesion to an ulcerated one with characteristic features including an indurated area and undermined edges that clinically resembled that of BU. Samples were collected for both PCR and F-TLC, and both turned out positive. He was immediately administered rifampicin $450 \mathrm{mg}$ daily and streptomycin $500 \mathrm{mg}$ twice daily. The patient was not admitted to the hospital but attended the clinic three times a week for wound dressing. After 8 weeks of treatment and dressing, the induration associated with the lesion and the size of the ulceration had reduced in diameter to a very small palpable nodule. The patient only required chemotherapy and wound management for complete healing. The overall treatment duration (including hospitalization/dressings) after which the patient was described as completely healed was 105 days. Figure 1 shows the progression of the healing process of Case 1. 

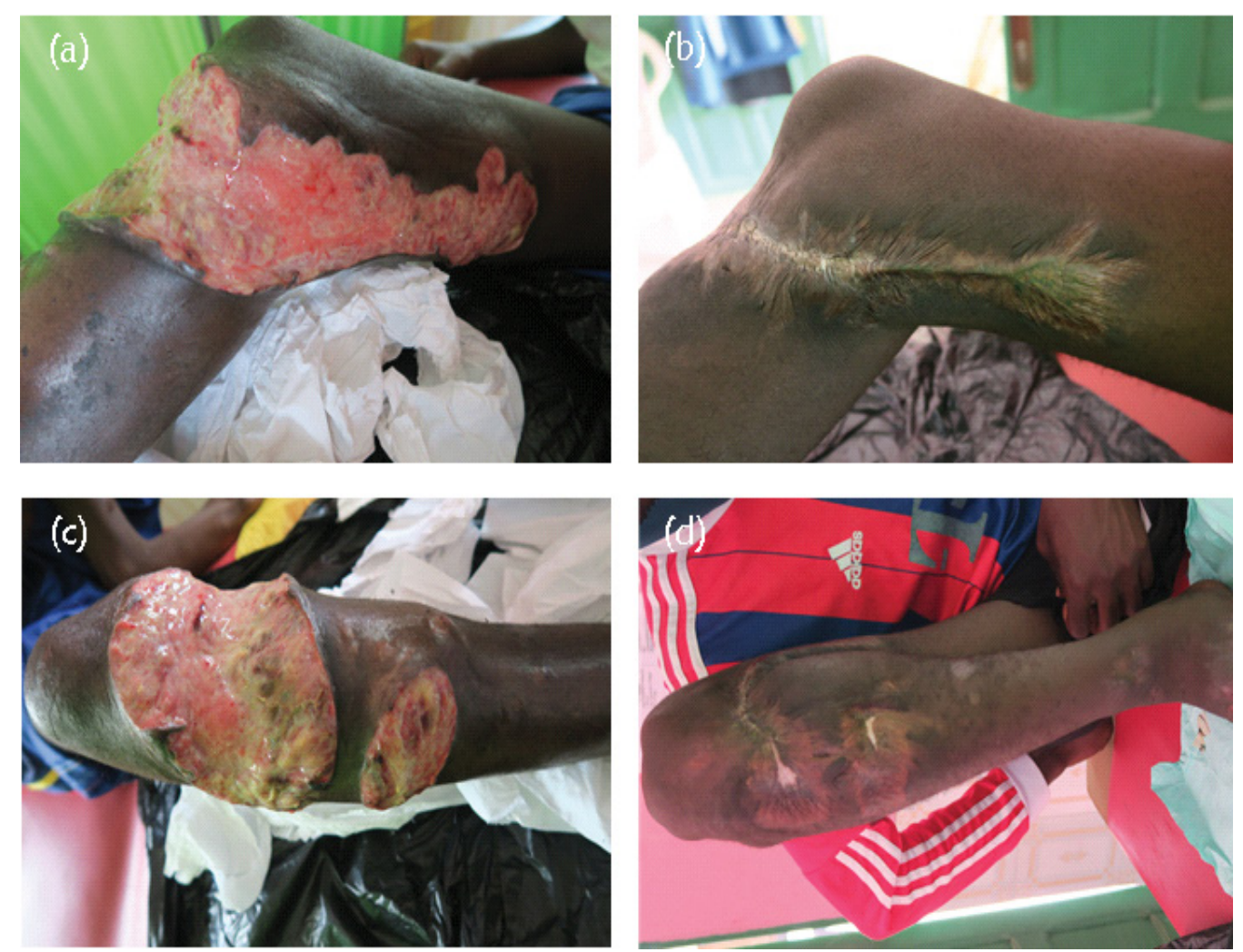

Figure 2: Mycobacterium ulcerans lesion on the right lower knee, thigh, and a leg on (a,c) reporting (January 9, 2019) before the start of antibiotics, and $(b, d)$ after healing.
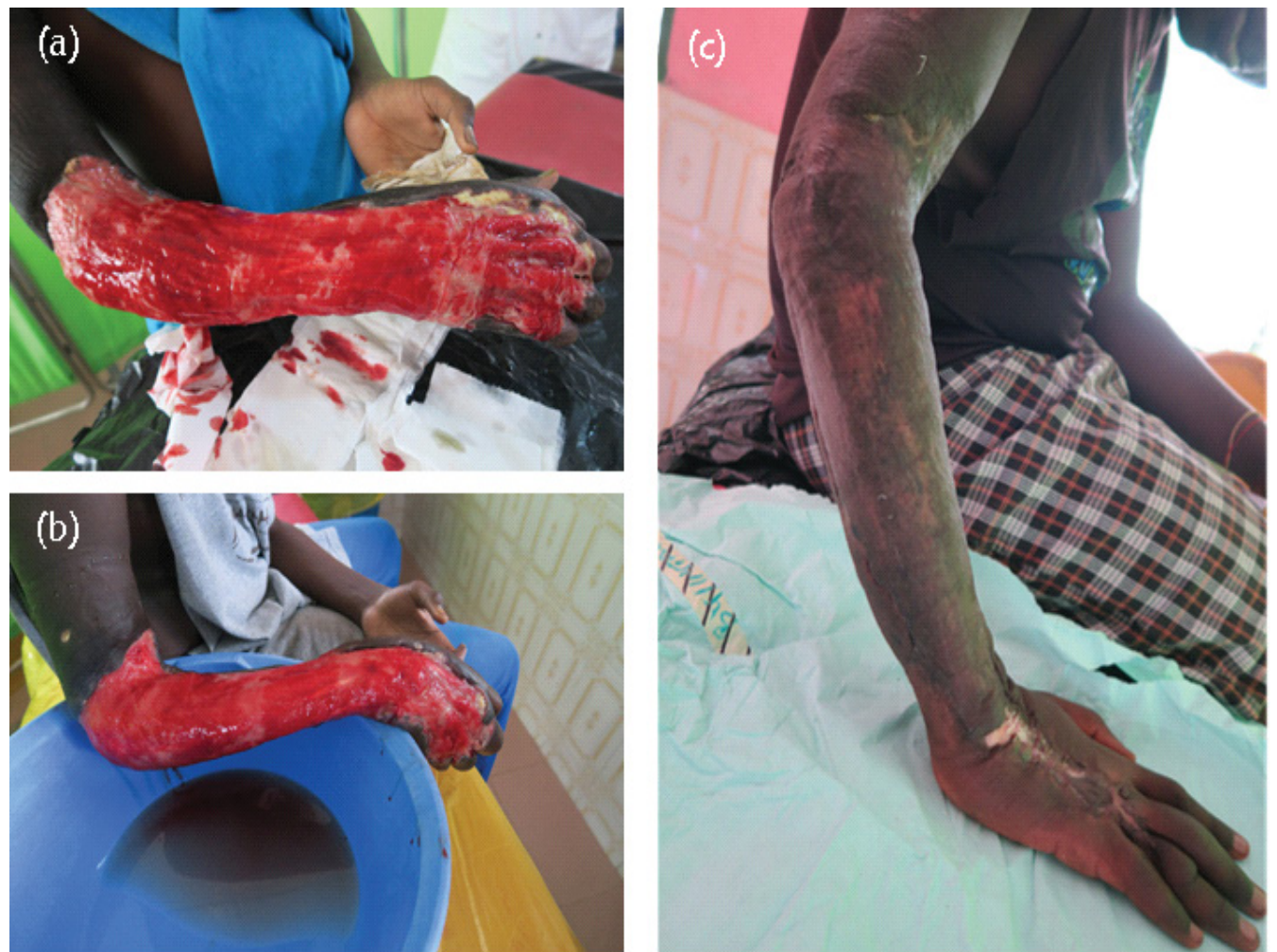

Figure 3: Large ulcer with extensive necrosis. Mycobacterium ulcerans lesion on right upper limb/arm and forearm (a) on reporting day (July 24,2019$)$ and before the start of antibiotics; (b) 8 weeks after the start of antibiotics, and (c) post-surgical debridement.

\section{Case 2}

Case 2 was a 17-year-old boy from Asuboi in the Ayensuanu (Suhum-Kraboa-Coaltar) district of the
Eastern region, a largely understudied BU endemic area in Ghana. He reported to the GWMH Buruli Ward on January 9, 2019, with an extensive multifocal category III lesion. The lesions were located on the right lower 
limb-to-knee, thigh, and leg respectively (Figure 2). The patient had received traditional herbal treatment and reported to the health facility when the ulcer had progressed into advanced stages. At the time of presentation to the hospital, the patient could not walk and was brought in a wheelchair. He had a loss of flexion at the knee joint resulting in functional limitation and restricted range of motion (ROM). Consequently, the patient had difficulty in standing, squatting, sitting, walking, or negotiating stairs.

An initial clinical diagnosis of BU was made based on a granulomatous appearance of the lesions. Swab samples from the multiple lesions were collected for laboratory diagnosis. The lesion on the knee was PCR negative for $\mathrm{BU}$ while the swab of the second ulcerative lesion on the lower right leg was PCR positive for $M$. ulcerans. He was hospitalized for comprehensive wound management. He commenced BU treatment on January 23,2019 , with oral rifampicin $600 \mathrm{mg}$ daily and clarithromycin $500 \mathrm{mg}$ twice daily until March 16, 2019. Because of the late reporting, other interventions than the prescribed antibiotics were required. The case required a longer period (553 days) before the patient was declared healed and discharged. He had limitations in joint movement as treatment progressed and run the risk of disfigurement, contractures, and disability. To circumvent this, intensive physiotherapy was prescribed for him to release the joint contractures. The physiotherapy helped to regain his normal functional ability by eradicating pain and swelling, improving muscular strength, improving joint stability, improving joint flexibility and ROM. The patient was also encouraged to indulge in the activities concerned with daily life routines including activities in his school environment. These helped the patient to the extent that at the time of complete healing, he could play football. Figure 2 shows the progression of the healing process of Case 2.

\section{Case 3}

Case 3 was a fourteen-year-old boy who was admitted to the Buruli Ward of the Ga West Municipal Hospital, Amasaman on July 24, 2019. He reported to the facility with a large category III lesion (> $15 \mathrm{~cm}$ in diameter) located on the right arm. The patient reported late to the facility in a deteriorated state with uncontrolled pain in the area of the ulceration. He had been referred from the Western Region of Ghana to the Buruli Ward of Ga West Municipal Hospital, Amasaman after an initial PCR positive result. Upon admission, he was immediately put on a daily wound management regime. The case was complicated as he reported severe secondary bacterial infections resulting in acute pain. General antibiotics were co-administered to tackle secondary bacterial infections. His right arm was completely ulcerated with only a small skin hanging under his arm and the fingers of the affected arm were swollen resulting in some limitations to their use. He was hospitalized and given daily wound dressing at the initial stages and later reduced to thrice weekly. While the general antibiotic treatment was going on, the pain was minimized by carefully reducing the slough in the lesion. Also, swab samples were collected at the same time for repeat $M$. ulcerans specific IS2404 PCR analysis and mycolactone specific $\mathrm{f}-\mathrm{TLC}$ analysis. The result returned positive for both PCR and f-TLC. He was therefore put on oral rifampicin $600 \mathrm{mg}$ daily and clarithromycin 500 $\mathrm{mg}$ twice daily for 53 days ( 8 weeks). The antibiotic treatment commenced on August 14, 2019, and was ended on October 5, 2019. Despite 8-week antibiotics, there was no clinically significant improvement hence he was recommended for further interventions to generate a healthy base for healing and promote healing of the ulcer. Subsequently, he underwent surgery (debridement plus skin graft) on December 28, 2019, to remove hyper granulation tissue to speed up the healing of the ulcer. On February 10, 2020, the right upper limb ulcer was cleaned thoroughly and closed with a split skin graft under general anesthesia with transplantation of healthy skin taken from the right thigh and secured with chromic catgut 4.0. Wound dressings were applied to both the recipient and donor sites. After the surgery, he also developed a hypertrophic scar over the donor site, the right thigh (approximately the $4 \%$ total body surface area) which was managed with a pressure garment and scar massage with shea butter. The graft healed well, however it left behind swelling and limitations in joint movement, especially in the finger region. Therefore, postoperative management such as physiotherapy and ROM exercises were initiated to prevent or reduce oedema formation, and to allow maximum functional ability by maintaining or improving the mobility of all the joints of the affected arm and fingers. After the interventions, the functional mobility of the grafted arm had significantly improved and the ROM of the elbow region was essentially normal. However, the fingers of the involved hand where there was injury and skin loss had a significant decrease in ROM (Figure 3d). Overall, the patient spent a total of 357 days for the closure of the ulcer to be completely healed. Figure 3 shows the evolution of Case 3 from the day he reported and was admitted to the facility until he had completely healed and discharged.

\section{Case 4}

Case 4 was a 45 -year-old man from Odumase in the Ga West Municipality who had presented to the Buruli Unit of the Ga West Municipal Hospital, Amasaman on September 26, 2019, with a typical BU lesion on the left lower limb. Based on the clinical signs and symptoms, an initial clinical diagnosis of BU was made by clinicians. Swab samples were collected for both $M$. ulcerans specific IS2404 PCR and mycolactone specific $\mathrm{f}-\mathrm{TLC}$ diagnosis. The patient was promptly diagnosed 

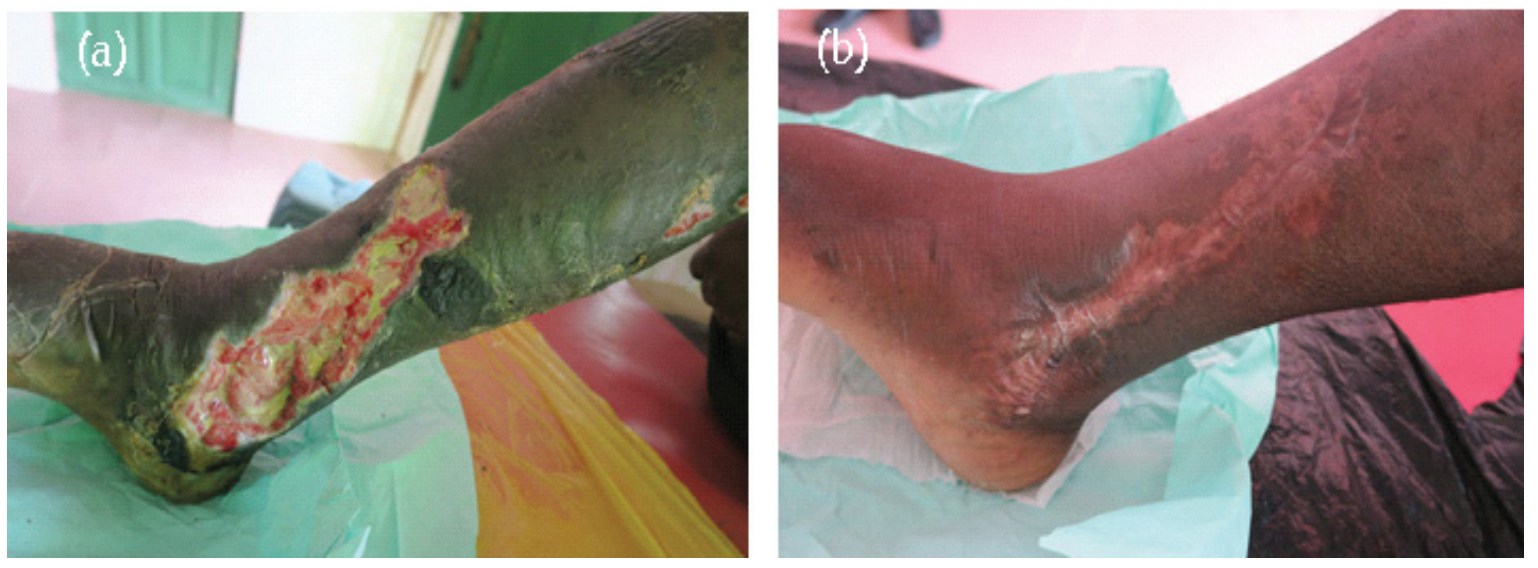

Figure 4: Mycobacterium ulcerans lesion on the right lower limb (a) on reporting (September 26, 2019) and before the start of antibiotics, and (b) 8 weeks after the start of antibiotics and healed completely on February 17, 2020.

based on positive results for both PCR and f-TLC. He commenced antibiotics treatment with rifampicin 450 $\mathrm{mg}$ daily and streptomycin $500 \mathrm{mg}$ twice daily. He was not admitted to the hospital; however, he attended the clinic three times a week for wound dressing and monitoring. No surgical debridement or reconstruction was required. The lesion healed completely after the completion of the 8-week course of rifampicin and streptomycin treatment coupled with appropriate wound management in a total of 144 days. There was no permanent disability or limitation of ROM at the ankle joint. Furthermore, the patient was able to indulge in all the activities concerned with his daily life routines including riding a motorcycle to the clinic for reviews. Figure 4 shows the progression of the healing process of Case 4.

\section{Discussion}

Buruli ulcer is a major health issue in endemic communities, resulting in huge economic costs to the patient and the society as a whole. The mode of transmission of BU is still not fully understood; hence current management and control strategy is centred primarily on early identification of cases, correct and early diagnosis $[24,25]$, prompt antimycobacterial treatment [11], and wound management [26]. These have helped in drastically reducing the need for surgical intervention (debridement, skin grafting, and/ or amputation), physiotherapy, and/or hospitalization $[27,28]$. In addition, quality wound management plays a significant role in the reduction of the time to healing as well as decreasing the risk for secondary infection, and morbidity [29].

Our emphasis in this retrospective case study is to highlight concerted, holistic, and integrated management strategies that significantly improved wound healing outcomes among four different Buruli ulcer cases that were managed at the Ga West Municipal Hospital in Ghana. The multidisciplinary holistic approach has been beneficial in the successful treatment and healing of difficult-to-treat diabetic foot ulcers [30,31].

Though the knowledge about the aetiology of BU has generally improved in affected Ghanaian communities because of the public sensitization and education, Buruli ulcer patients often wait long after their first symptoms begin before going to the hospital. Previous reports show that the trend is prevalent in Africa [3234], and in Australia [35] where patients present more advanced stages of the disease to hospitals, including osteomyelitis. For instance, the proportion of cases in category III (late-stage) in endemic countries at diagnosis stands at 30\% currently [36] and the late reporting has great consequences on the management of the disease. For example, patients who were managed by antibiotic treatment alone, reported prolonged wound healing times, high rates of treatment toxicity, and significant tissue destruction associated with severe paradoxical reactions $[37,38]$. True as it may be that $M$. ulcerans disease could be cured with antibiotics alone as previously suggested [24], this should be viewed in terms of the time of reporting to the hospital. For instance, it has previously been noted that early (less than six-months-old) presentation and smaller (less than $10 \mathrm{~cm}$ diameter) lesions lead to complete cure without surgery [21]. Furthermore, the effectiveness of the combined rifampicin and streptomycin [11] coupled with early diagnosis $[24,25]$ contributed to this outcome. Cases 1 and 4 were seen early by the experts hence had early diagnosis and early treatment was instituted. Consequently, they healed completely after completion of the 8-week course of rifampicin and streptomycin treatment [39]. The lesions healed without recourse to any other adjunct surgical treatment except properly instituted wound management protocols.

On the other hand, with late reporting, antibiotic treatment alone is not sufficient for complete healing $[24,40,41]$. Sometimes additional interventions including wide surgical excision and skin grafting may be required to enhance the rate of healing in specific ulcers. Two of the cases (case 2 and case 3 ) in this case report were brought to the hospital at a more advanced 
stage (Category III) of M. ulcerans disease. Thus, they were hospitalized for a long period resulting in a higher corresponding cost of management. It took longer for their wounds to heal with a plausible risk of toxicity due to the medications administered, and the potential for significant tissue destruction associated with severe paradoxical reactions $[37,38]$. BU infection is typically not painful [29], however, Case 3 had acute pain which was attributed to the secondary infections.

The case report also underscored the importance of effective and intensive physiotherapy and long-term rehabilitation that was instituted to help in the release of joint contractures and correcting deformities in these healed BU cases. This has led to the prevention of permanent deformation and disability of patients who had completely healed. Postoperative or otherwise physiotherapy has been demonstrated to play a major role in anterior cruciate ligament $(A C L)$ rehabilitation and maximum functional ability among patients [42].

Lastly, all four reported cases received proper wound care on a need basis to be either daily basis or thrice weekly depending on the severity of lesions [43]. Dressings were found to be very painful but very effective in halting the deterioration of ulcers. Healing was achieved rapidly and prolonged periods of disability and co-morbidities were prevented [44].

\section{Conclusion}

The retrospective case study highlights the positive outcomes from an integrated approach to the management and treatment of four Buruli ulcer cases at Ga West Municipal Hospital in Ghana. The management of each of the cases was patient-specific depending on the lesion category, time of reporting, etc. Out of the four cases treated and discharged, Case 1 and Case 4 reported early to the facility and only antibiotic treatment and wound management were sufficient for complete healing. The duration of hospitalizations of these cases was short. Case 2 and Case 3 on the other hand, reported with advanced stages of ulceration. In addition to the antibiotic treatment and wound management, Case 2 and Case 3 requiring physiotherapy and ROM exercises to correct contractures left behind after healing. Furthermore, surgical interventions including debridement and skin grafting were required for Case 3. Employing the integrated management approach led to full recovery of all the patients, albeit with different times to healing depending on the severity of the lesions (Supplementary Materials).

\section{Declarations}

\section{Ethics approval and consent to participate}

All four patients consent both verbally and written to participate in the study. In the case of the minor, consent from a parent or guardian was obtained for the collection of data and noted in the patient medical record.

\section{Consent for publication}

Consent was obtained from the patients for publication of this Case report and any accompanying images.

\section{Availability of data and materials}

All data is contained in the manuscript.

\section{Competing interests}

The authors declare that they have no competing interests.

\section{Funding}

The case report was funded by World Health Organization (WHO) and ANESVAD. The WHO provided the initial training and resources for the study while ANESVAD provided equipment, supplies, and vehicle for the routine visit to the clinic.

\section{Authors contributions}

RA, JT, and AA conceptualized the study, RA and GAA drafted the manuscript, JP, JT, NKK, and AP revised the manuscript. GAA and RA were responsible for the f-TLC analysis while AA was responsible for the PCR analysis. GA, AAC, and SKD were involved in the care of the patients. JT, JP, and AP were responsible for the surgical management of the patients. All authors made important contributions and have read and approved the final version of the manuscript.

\section{Acknowledgments}

The authors would like to thank the World Health Organization and ANESVAD for the generous funding of this work. They are also thankful to Professor Kishi Yoshito of Harvard University for the donation of the synthetic mycolactone for the study. We are also grateful to the National Buruli Ulcer Control Program (NBUCP) for generously donating the antibiotics for the treatment, and for their supervisory role. Furthermore, we thank the staff of the Ga West Municipal Hospital, particularly the BU ward, and the Bacteriology Unit of Noguchi Memorial Institute for Medical Research (NMIMR) for their help and support. Finally, our gratitude goes to all the patients and their caregivers presented in the case report.

\section{References}

1. Ukwaja KN, Meka AO, Chukwuka A, Asiedu KB, Huber KL, et al. (2016) Buruli ulcer in nigeria: Results of a pilot case study in three rural districts. Infect Dis Poverty 5: 39.

2. Huang GKL, Johnson PDR (2014) Epidemiology and management of buruli ulcer. Expert review of anti-infective therapy 12: 855-865.

3. WHO (2019) Buruli ulcer (Mycobacterium ulcerans infection).

4. Kanga JM, Kacou ED (2001) [Epidemiological aspects of buruli ulcer in cote d'Ivoire: Results of a national survey]. Bull Soc Pathol Exot 94: 46-51. 
5. Debacker M, Aguiar J, Steunou C, Zinsou C, Meyers WM, et al. (2004) Mycobacterium ulcerans disease (Buruli ulcer) in rural hospital, Southern Benin, 1997-2001. Emerg Infect Dis 10: 1391-1398.

6. Bratschi MW, Bolz M, Minyem JC, Grize L, Wantong FG, et al. (2013) Geographic distribution, age pattern and sites of lesions in a cohort of buruli ulcer patients from the mape basin of cameroon. PLoS Negl Trop Dis 7: e2252.

7. Phanzu DM, Suykerbuyk $P$, Saunderson $P$, Lukanu $P N$ Minuku JBM, et al. (2013) Burden of mycobacterium ulcerans disease (buruli ulcer) and the underreporting ratio in the territory of songololo, democratic republic of congo. PLoS Negl Trop Dis 7: e2563.

8. Amofah G, Bonsu F, Tetteh C, Okrah J, Asamoa K, et al (2002) Buruli ulcer in ghana: Results of a national case search. Emerg Infect Dis 8: 167-170.

9. Amofah GK, Sagoe-Moses C, Adjei-Acquah C, Frimpong EH (1993) Epidemiology of buruli ulcer in amansie west district, ghana. Trans R Soc Trop Med Hyg 87: 644-645.

10. Asiedu K, Raviglione MC, Scherpbier R (2000) Buruli ulcer: Mycobacterium ulcerans infection. World Health Organization.

11. WHO (2012) Treatment of mycobacterium ulcerans disease (buruli ulcer): Guidance for health workers.

12. Portaels $F$ (2014) Laboratory diagnosis of buruli ulcer: A manual for health care providers. World Health Organization.

13. WHO (2004) Provisional guidance on the role of specific antibiotics in the management of mycobacterium ulcerans disease (Buruli ulcer).

14. Wadagni AC, Barogui YT, Johnson RC, Sopoh GE, Affolabi $D$, et al. (2018) Delayed versus standard assessment for excision surgery in patients with Buruli ulcer in Benin: $A$ randomised controlled trial. Lancet Infect Dis 18: 650-656.

15. Asiedu K, Etuaful S (1998) Socioeconomic implications of buruli ulcer in ghana: A three-year review. Am J Trop Med Hyg 59: 1015-1022.

16. Schutte D, Um-Boock A, Mensah-Quainoo E, Itin $P$, Schmid P, et al. (2007) Development of highly organized lymphoid structures in Buruli ulcer lesions after treatment with rifampicin and streptomycin. PLoS Negl Trop Dis 1: e2.

17. World Health Organization (2008) Buruli ulcer: Progress report,2004-2008. Weekly Epidemiological Record 83: 145154.

18. Pak J, O'Brien DP, Quek T, Athan E (2012) Treatment costs of mycobacterium ulcerans in the antibiotic era. Int Health 4: 123-127.

19. Yeboah-Manu D, Kpeli GS, Ruf MT, Asan-Ampah K, Quenin-Fosu K, et al. (2013) Secondary bacterial infections of buruli ulcer lesions before and after chemotherapy with streptomycin and rifampicin. PLoS Negl Trop Dis 7: e2191.

20. Johnson PDR (2010) Should antibiotics be given for Buruli ulcer? Lancet 375: 618-619.

21. Nienhuis WA, Stienstra $Y$, Thompson WA, Awuah PC, Abass KM, et al. (2010) Antimicrobial treatment for early, limited Mycobacterium ulcerans infection: A randomised controlled trial. Lancet 375: 664-672.

22. Johnson PDR, Stinear T, Small PLC, Pluschke G, Merritt RW, et al. (2005) Buruli ulcer (M. ulcerans infection): New insights, new hope for disease control. PLoS Med 2: e108.

23. Lehman L, Simonet V, Saunderson P, Agbenorku P (2007) Buruli ulcer: Prevention of disability (POD). WHO.
24. Chauty A, Ardant MF, Adeye A, Euverte H, Guedenon A, et al. (2007) Promising clinical efficacy of streptomycinrifampin combination for treatment of buruli ulcer (Mycobacterium ulcerans disease). Antimicrob Agents Chemother 51: 4029-4035.

25. Sarfo FS, Phillips R, Asiedu K, Ampadu E, Bobi N, et al. (2010) Clinical efficacy of combination of rifampin and streptomycin for treatment of Mycobacterium ulcerans disease. Antimicrob Agents Chemother 54: 3678-3685.

26. Sakyi SA, Aboagye SY, Otchere ID, Liao AM, Caltagirone TG, et al. (2016) RNA aptamer that specifically binds to mycolactone and serves as a diagnostic tool for diagnosis of buruli ulcer. PLoS Negl Trop Dis 10: e0004950.

27. Meka AO, Chukwu JN, Nwafor CC, Oshi DC, Madichie NO, et al. (2016) Diagnosis delay and duration of hospitalisation of patients with buruli ulcer in nigeria. Trans $\mathrm{R}$ Soc Trop Med Hyg 110: 502-509.

28. Chukwu JN, Meka AO, Nwafor CC, Oshi DC, Madichie NO, et al. (2017) Financial burden of health care for buruli ulcer patients in nigeria: The patients' perspective. Int Health 9: 36-43.

29. Alferink M, de Zeeuw J, Sopoh G, Agossadou C, Abass KM, et al. (2015) Pain associated with wound care treatment among buruli ulcer patients from ghana and benin. PLoS One 10: e0119926.

30. Alkhatieb M, Mortada H, Aljaaly H (2020) Management of a difficult-to-treat diabetic foot wound complicated by osteomyelitis: A case study. Case Rep Surg 2020: 3971581.

31. Chawla S (2005) Diabetic foot ulcer-a case study. Journal of Exercise Science and Physiotherapy 1: 98-99.

32. Vincent QB, Ardant MF, Adeye A, Goundote A, SaintAndre JP, et al. (2014) Clinical epidemiology of laboratoryconfirmed buruli ulcer in benin: A cohort study. Lancet Glob Health 2: e422-e430.

33. Noeske J, Kuaban C, Rondini S, Sorlin P, Ciaffi L, et al. (2004) Buruli ulcer disease in cameroon rediscovered. Am J Trop Med Hyg 70: 520-526.

34. Marion E, Carolan K, Adeye A, Kempf M, Chauty A, et al. (2015) Buruli ulcer in south western nigeria: A retrospective cohort study of patients treated in Benin. PLoS Negl Trop Dis 9: e3443.

35. Boyd SC, Athan E, Friedman ND, Hughes A, Walton A, et al. (2012) Epidemiology, clinical features and diagnosis of mycobacterium ulcerans in an australian population. Med $\mathrm{J}$ Aust 196: 341-344.

36. WHO (2020) Ending the neglect to attain the sustainable development goals: A road map for neglected tropical diseases 2021-2030.

37. O'Brien DP, Friedman ND, McDonald A, Callan P, Hughes A, et al. (2018) Wound healing: Natural history and risk factors for delay in australian patients treated with antibiotics for mycobacterium ulcerans disease. PLoS Negl Trop Dis 12: e0006357.

38. O'Brien DP, Callan P, Friedman ND, Athan E, Hughes A, et al. (2019) Mycobacterium ulcerans disease management in Australian patients: The re-emergence of surgery as an important treatment modality. ANZ J Surg 89: 653-658.

39. Abass KM, van der Werf TS, Phillips RO, Sarfo FS, Abotsi $\mathrm{J}$, et al. (2015) Buruli ulcer control in a highly endemic district in ghana: Role of community-based surveillance volunteers. Am J Trop Med Hyg 92: 115-117.

40. Saka B, Landoh D, Kobara B, Djadou K, Yaya I, et al. (2013) 
Profile of buruli ulcer treated at the national reference centre of togo: A study of 119 cases. Bull Soc Pathol Exot 106: 32-36.

41. Ackumey MM, Kwakye-Maclean C, Ampadu EO, de Savigny D, Weiss MG (2011) Health services for Buruli ulcer control: Lessons from a field study in Ghana. PLoS Negl Trop Dis 5: e1187.

42. Shah N (2008) Increasing knee range of motion using a unique sustained method. N Am J Sports Phys Ther 3: 110113.
43. Velink A, Woolley RJ, Phillips RO, Abass KM, van der Werf TS, et al. (2016) Former buruli ulcer patients' experiences and wishes may serve as a guide to further improve buruli ulcer management. PLoS Negl Trop Dis 10: e0005261.

44. Macdonald JM, Geyer MJ, WHO (2010) Wound and lymphoedema management/edited by John M. Macdonald and Mary Jo Geyer. 